\title{
Editorial
}

\section{Managing hyperglycaemia in hospitalized patients}

\author{
Sri Lanka Journal of Diabetes, Endocrinology and Metabolism 2012; 2: 55-56
}

Hyperglycaemia is a common, serious and costly health care problem in hospitalized patients. There is substantial observational evidence linking hyperglycaemia in critically ill patients (with and without diabetes) to higher rates of hospital complications, longer hospital stay, higher health care resource utilization, and greater hospital mortality $(1,2)$. Although several cohort studies as well as early randomized clinical trials (RCTs) suggested that tight glucose control (80 to $110 \mathrm{mg} / \mathrm{dL}$ [4.4 to $6.1 \mathrm{mmol} / \mathrm{L}$ ]) reduced hospital complications and mortality $(3,4)$, this target has been difficult to achieve without increasing the risk for severe hypoglycaemia. In addition, recent RCTs in critically ill patients have failed to show a significant improvement in mortality or have even shown increased mortality risk with intensive glycaemic control (5-7).

\section{Managing hyperglycaemia in Intensive Care Settings}

In NICE-SUGAR, a multicentre, multinational RCT, tested the effect of tight glycaemic control (target 81-108 $\mathrm{mg} / \mathrm{dl}$ ) on outcomes among 6,104 critically ill participants (5). Ninety-day mortality was significantly higher in the intensive vs. the conventional group (target 144-180 $\mathrm{mg} / \mathrm{dl}$ ) (78 more deaths; $27.5 \%$ versus $24.9 \%, \mathrm{P}=0.02$ ) in both surgical and medical patients. Mortality from cardiovascular causes was more common in the intensive group ( $41.6 \%$ versus $35.8 \% ; \quad \mathrm{P}=0.02)$. Severe hypoglycaemia was also more common in the intensively treated group ( $6.8 \%$ vs. $0.5 \%$; $\mathrm{P}<0.001)$. This study's findings do not disprove the notion that glycaemic control in the ICU is important; however, it strongly suggests that it is not necessary to target blood glucose values $<140 \mathrm{mg} / \mathrm{dl}$, and that a highly stringent target of $<110 \mathrm{mg} /$ dl may actually be dangerous.

In a recent meta-analysis of 26 trials $(\mathrm{N}=13,567)$, the pooled relative risk (RR) of death with intensive insulin therapy was 0.93 as compared with conventional therapy (95\% CI 0.83-1.04) (6). The pooled hypoglycaemia RR with intensive therapy was $6.0(95 \% \mathrm{Cl} 4.5-8.0)$. The specific ICU setting influenced the findings, with patients in surgical ICUs appearing to benefit from intensive insulin therapy (RR 0.63, 95\% Cl 0.44-0.91), while those in other critical care settings did not (medical ICU: RR 1.0, 95\% Cl 0.78-1.28; 'mixed’ICU: RR 0.99, 95\% Cl 0.86-1.12).

Based on recent RCTs, the Endocrine Society and ADA recommended raising glycaemic targets in the ICU. For the majority of patients in the ICU setting, using insulin infusion and targeting blood glucose levels between 140 and $180 \mathrm{mg} / \mathrm{dL}$ (7.8 and $10.0 \mathrm{mmol} / \mathrm{L}$ ) is recommended (8). Despite the lack of strong scientific evidence, lower glucose targets between 110 and $140 \mathrm{mg} / \mathrm{dl}$ (6.1 and 7.8 $\mathrm{mmol} / \mathrm{L}$ ) may be appropriate in selected ICU patients such as CABG surgical patients and stable glycaemic control patients without hypoglycaemia. Blood glucose targets $>180 \mathrm{mg} / \mathrm{dl}$ or $<110 \mathrm{mg} / \mathrm{dl}$ are not recommended.

\section{Managing hyperglycaemia in inward settings}

In general medical and surgical non-ICU patients, observational and RCT have also shown a strong association between hyperglycaemia and poor clinical outcomes, including prolonged hospital stay, infection, and disability after hospital discharge, and death $(9,10)$. In such patients, the presence of hyperglycaemia is associated with prolonged hospital stay, infection, disability after hospital discharge, and death $(1,9,11)$. Hyperglycaemia on admission has also been linked to worse outcomes in patients with community-acquired pneumonia (12).

In a prospective cohort multicentre study of 2,471 patients, those with admission glucose levels of $>11 \mathrm{mmol} /$ L (198 mg/dL) had a greater risk of mortality and complications than those with glucose $<11 \mathrm{mmol} / \mathrm{L}$. The risk of in-hospital complications increased 3\% for each 1 $\mathrm{mmol} / \mathrm{L}$ increase in admission glucose. In a retrospective study of 348 patients with chronic obstructive pulmonary disease and respiratory tract infection, the relative risk of death was 2.10 in those with a blood glucose of 7-8.9 $\mathrm{mmol} / \mathrm{L}$, and 3.42 for those with a blood glucose of $>9.0$ $\mathrm{mmol} / \mathrm{L}$ compared to patients with a blood glucose 6.0 $\mathrm{mmol} / \mathrm{L}$ (13). Each $1 \mathrm{mmol} / \mathrm{L}$ (18 mg/dL) increase in blood glucose was associated with a $15 \%$ increase in the risk of an adverse clinical outcome, which was defined as death or length of stay of greater than nine days. A recent RCT reported that improving glycaemic control with basalbolus vs. sliding scale insulin (SSI) in patients with type 2 diabetes undergoing general surgery reduced a composite of postoperative complications, including wound infection, pneumonia, bacteremia, respiratory and acute renal failure. In this study, a mean daily glucose concentration after the 1st day of basal-bolus and SSI was $145 \pm 32 \mathrm{mg} / \mathrm{dl}$ and $172 \pm 47 \mathrm{mg} / \mathrm{dL}$, respectively, $\mathrm{p}<0.01$. There were reductions with basal bolus as compared with SSI in the composite outcome (24.3\% and 8.6\%, OR: 3.39 [95\% Cl: 1.50-7.65]; $\mathrm{p}=0.003$ ). 


\section{Achieving safe and effective glycaemic targets}

Insulin therapy is the preferred method of glycaemic control in the majority of patients in the hospital setting (8). In the ICU, IV infusion is the preferred route of insulin administration. Numerous examples of successful Continuous Insulin Infusion algorithms in achieving glycaemic control are reported in the literature $(3,4,14)$. A computer-based algorithms aiming to direct the medical staff in adjusting insulin infusion rate have become commercially available. All published ICU insulin algorithms appear to be equally effective in controlling blood glucose without major clinical outcome differences, including frequency of severe hypoglycaemic events, length of ICU and hospital stay, or mortality, among different treatment algorithms $(1,8)$. Outside of critical care units, subcutaneous insulin administration is used much more frequently. Oral agents have a limited role, and should be avoided in the inpatient setting. Scheduled subcutaneous insulin is the preferred method for achieving and maintaining glucose control in non-ICU patients with diabetes or stress hyperglycaemia. The recommended components of inpatient subcutaneous insulin regimens include a basal, nutritional and a supplemental (correction) component $(1,8)$. Hospitalized patients often require high insulin doses to achieve target glucose levels due to increased insulin resistance; thus, in addition to basal and nutritional insulin requirements, patients often require supplemental or correction insulin for treatment of hyperglycaemia. Use of repeated doses of short-acting insulin per sliding scale, as a sole form of therapy in hospitalized patients with diabetes, should be avoided because of persistence of hyperglycaemia in type 2 diabetes and risk of ketoacidosis in patients with type 1 diabetes (8). The use of a basal-bolus regimen has been shown to improve glycaemic control with a similar rate of severe hypoglycaemia than SSI alone and to decrease hospital complications in patients undergoing non-cardiac surgery.

Considering above, it could be highlighted that hyperglycaemia is associated with poor outcomes in the hospital not only in patients with diabetes but also without diabetes with hyperglycaemia. It is evident that good metabolic control with target blood sugars are associated with improved hospital outcomes.

\section{- Dr. Uditha Bulugahapitiya}

Editor

\section{References}

1. Clement S, Braithwaite SS, Magee MF, et al. Management of diabetes and hyperglycaemia in hospitals. Diabetes Care 2004; 27(2): 553-97.

2. Inzucchi SE. Clinical practice. Management of hyperglycaemia in the hospital setting. N Engl J Med 2006; 355(18): 1903-11.
3. Furnary AP, Gao G, Grunkemeier GL, et al. Continuous insulin infusion reduces mortality in patients with diabetes undergoing coronary artery bypass grafting. $J$ Thorac Cardiovasc Surg 2003; 125(5): 1007-21.

4. van den Berghe G, Wouters P, Weekers F, et al. Intensive insulin therapy in the critically ill patients. $N$ Engl J Med 2001; 345(19): 1359-67.

5. Finfer S, Chittock DR, Su SY, et al. Intensive versus conventional glucose control in critically ill patients. $N$ Engl J Med 2009; 360(13): 1283-97.

6. Griesdale DE, de Souza RJ, van Dam RM, et al. Intensive insulin therapy and mortality among critically ill patients: a meta-analysis including NICE-SUGAR study data. Canadian Medical Ass Journal 2009; 180(8): 821-7.

7. Preiser JC, Devos P, Ruiz-Santana S, et al. A prospective randomized multi-centre controlled trial on tight glucose control by intensive insulin therapy in adult intensive care units: the Glucontrol study. Intensive Care Med 2009.

8. Moghissi ES, Korytkowski MT, DiNardo M, et al. American Association of Clinical Endocrinologists and American Diabetes Association consensus statement on inpatient glycaemic control. Diabetes Care 2009; 32(6): 1119-31.

9. Umpierrez GE, Isaacs SD, Bazargan N, You X, Thaler L M, Kitabchi A E. Hyperglycaemia: an independent marker of in-hospital mortality in patients with undiagnosed diabetes. J Clin Endocrinol Metab 2002; 87(3): 978-82.

10. Umpierrez GE, Simley D, Jacobs S, et al. Randomized Study of Basal Bolus Insulin Therapy in the Inpatient Management of Patients with Type 2 Diabetes Undergoing General Surgery (RABBIT 2 Surgery). Diabetes Care 2011; 34(2): 256-61.

11. Pomposelli JJ, Baxter JK, Babineau TJ, et al. Early postoperative glucose control predicts nosocomial infection rate in diabetic patients. JPEN J Parenter Enteral Nutrr 1998; 22(2): 77-81.

12. McAlister FA, Majumdar SR, Blitz S, Rowe BH, Romney J, Marrie TJ. The relation between hyperglycaemia and outcomes in 2,471 patients admitted to the hospital with community-acquired pneumonia. Diabetes Care 2005; 28(4): 810-5.

13. Baker EH, Janaway CH, Philips BJ, et al. Hyperglycaemia is associated with poor outcomes in patients admitted to hospital with acute exacerbations of chronic obstructive pulmonary disease. Thorax 2006; 61(4): 284-9.

14. Goldberg PA, Siegel MD, Sherwin RS, et al. Implementation of a safe and effective insulin infusion protocol in a medical intensive care unit. Diabetes Care 2004; 27(2): 461-7. 